\title{
Powering Social Media Footage: Simple Guide for the Most Vulnerable to Make Emergency Visible
}

Marvin Starominski-Uehara, $\mathrm{PhD}^{*}$

\begin{abstract}
Eyewitness media was boosted by ubiquitous smartphones and social media use. User-generated content by non-professionals, or netizens, has shed light on issues they deem important by capturing and sharing footage appealing to their inner digital network and mainstream media. However, the influence that digital testimonials exerts on activism and indexing has been restricted to those possessing some media training. This paper aims to fill this gap by providing a framework to guide vulnerable people experiencing harsh conditions to leverage the power of social media. The expectation is that such a guideline would help the most vulnerable draw the attention of other members of the community, authorities and mainstream media to the conditions they are in. The proposal of this framework is based on the theory of mediatized conflict and analysis of the hashtag \#FallecidosCovid19Ec on Twitter. This hashtag helped organize scattered experiences, raise media attention and pressure officials to respond to urgent demands.
\end{abstract}

Keywords: user-generated content; video activism; indexing; social media; covid-19; Ecuador

${ }^{*}$ Risk Management Consultant, Japan. muehara79@gmail.com

\section{Introduction}

Politicians are susceptible to mainstream news (Street, 2010). They are aware of the necessity to quickly respond to or debunk media narratives to enforce their agenda (Green-Pedersen \& Stubager, 2010). Authorities have resorted to social media platforms to address unfavorable media reports (Lee \& Xu, 2018). Social media platforms allow authorities to directly communicate with their constituents at their own pace and convenience (Yang et al., 2016). Authorities no longer rely on large media networks to reach society to spread and reinforce their political views (Hong \& Kim, 2016). The same is true for constituents. They can now directly and publicly reach politicians to voice their concerns and easily and quickly share experiences with others (Straus, \& Glassman, 2016). They can do so using text or image. 
Eyewitness media is a byproduct of this mode of direct and instant communication. People at the frontline can instantly share what they are seeing on the ground (Ristovska, 2016). They need, however, access to a smartphone and wireless connection to register and distribute these experiences. When these resources are absent, they rely on journalists or savvy citizens to uncover what is happening on the ground. This is what happened, for instance, during the covid-19 epidemic in the city of Guayaquil in Ecuador. After a local journalist exposed the collapse of the public health and emergency systems, this emergency quickly came under the mainstream media spotlight (MisionesOnline, 2020). This paper argues that the plight of the vulnerable in this Ecuadorian city could have been anticipated and further mitigated had citizens received some basic training on how to leverage the power of social media. This is the problem that this paper tackles. It does so by analyzing the development and structure of the content associated with the hashtag \#FallecidosCovid19Ec. The objective is to transfer this practical knowledge to those aiming to empower the most vulnerable with skills and resources that reduce risks observed in precarious livelihoods (Carr et al., 2018).

\section{Theory}

Mortensen (2014) lays out a theory on the role of eyewitness in contemporary journalism. Mortensen's theory is called mediatized conflict. Mortensen developed this theory out of previous work on mediatization theory. Mediatization argues that the media is an intrinsic part of institutions and organizations. The media is essential in shaping the perceptions of culture and society (Mortensen, 2014). Mediatized conflict explores the tension between opposing interests and strategies in the context of media and conflict (Mortensen, 2014).

Mortensen's theory specifically looks at the conflict between top-down and bottom-up efforts to produce and distribute media content. The top-down dimension is controlled by central authorities. They make use of institutionalized news media to push their vested interests (Mortensen, 2014). The bottom-up dimension consists of non-elite actors. These actors often challenge the elite framings of conflict. These non-professionals rely on social networks to spread news as they do not possess access to established media networks (Mortensen, 2014).

The advent of digital technologies has served as a springboard to the bottom-up movement. Camera phones connected to the Internet help non-professionals produce and circulate their 
images (Mortensen, 2014). Eyewitness recordings have already been part of many major conflicts and disasters since the terrorist attack in the US on September 11th, 2001 (Mortensen, 2014). Diffused recordings have helped governments respond to crises such as the Boston Marathon Bombing in 2013 and communities object top-down narratives like the abuse of inmates in the Abu Ghraib prison in 2004 (Mortensen, 2014). The battle between these two forces consist mainly on who can control and shape the public's mediated knowledge and experience of conflict (Mortensen, 2014).

Mortensen adds that the bottom-up movement faces critical challenges in its fight against institutionalized channels of communication. Mortensen (2014:4) explains that non-professional images are 'habitually considered authentic on account of their urgency, immediacy, and handheld 'amateur' aesthetics'. Amateur aesthetics, however, are generally not founded on objectivity, autonomy, and transparency, which are integral parts of standard journalistic procedure (Mortensen, 2014). The framework proposed in this article makes recommendations for non-professionals on how they can meet journalism standards while keeping the documentation of their experiences authentic.

\section{Method}

The covid-19 epidemic collapsed the public health and emergency systems in the city of Guayaquil, Ecuador. As a result, the sick started dying at home. The local government struggled to collect all the deceased. In response to this calamity, a local journalist created on March 31st, 2020, a thread on Twitter with the hashtag \#FallecidosCovid19Ec under which she started posting information on the deceased not collected from homes (Pesantes, 2020). This hashtag helped local authorities locate the bodies.

The news posted in this thread depicts the battle over narrative control. For instance, the first tweet of this journalist on the novel coronavirus happened on February 29th, 2020 (Pesantes, 2020a). The content of this tweet leads to an article in which local authorities aimed at setting expectations over an uncertain scenario. However, on March 21st, 2020, this journalist made public that the local government was struggling to collect all the dead bodies across the city (Pesantes, 2020b). 
One of the first recordings of an uncollected body in Ecuador posted on Twitter apparently caused by the novel coronavirus appeared on March 26th, 2020 (ManabaDice, 2020). This footage, from a hindsight, can be trusted. Its content, however, could not be immediately considered a reliable source as it could not be traced to the person who recorded it. Despite this shortcoming, the framework of such an account provides a guideline to be replicated by other people willing to bring attention to the dire situation they find themselves in.

Testimonial videos need to be short and focused (Finkler \& Leon, 2019). Media values content that are brief, unexpected and informative (Caple, 2018). Under these features, the framework of an impactful digital account can be divided into three parts: i) subject, ii) structure and iii) platform (Figure 1).

The subject part of the video covers three parts. Authorship attribution is facilitated when the person recording starts off revealing his/her identity and accurately informs where the event is taking place (Rocha et al., 2016). The next step is object description which requires a clear description of the problem (Campbell et al., 2018) from a first person narrative supported by visuals (Labrecque et al., 2020). In this description, it is also important to cite actions that attempted to amend this problem if they exist. The third step is emotional valence and this occurs by openly revealing how an experience has psychologically affected the author of the video (Nikolinakou, \& King, 2018).

As for the structure of testimonial digital footages, the issue under consideration needs to be engulfed in a sense of urgency and thus requiring immediate attention and action (Baccarella et al., 2018). The author's focus is on adding as much visual information as possible about the problem and its context (Grosser et al., 2019). The quality of the video itself is less important as viewers are not seeking for aesthetics but information cues that showcase that such a piece is genuine, original and trustworthy (Mortensen, 2014). The last step before publishing is carefully selecting the hashtags that will help the target audience, beyond the author's followers, locate this video and amplify the call for action (Enli \& Simonsen, 2018).

Hashtags need to be descriptive. They should be accompanied by a brief text explaining the main reason for publishing and distributing such a video. They serve to i) summarize a problem; 
ii) determine specific, regional and national locations; and iii) add a particular experience to a collective concern or movement already in place (Wang et al., 2016).

Platform is the last part of this guideline. The first choice is selecting the social media to transmit or submit the footage recorded. This paper suggests Twitter because of its simplicity and penetration in mass media networks and among decision makers (Krutka \& Carpenter, 2016). Twitter also helps users easily identify and connect with people facing similar issues (Jost et al. 2018). This platform also helps users directly send their content to journalists and politicians by adding their usernames to messages. This direct mode of communication ensures that a problem is publicly registered under the attention of authorities responsible for addressing it (Shapiro \& Hemphill, 2017).

Users uploading original content onto social media platforms need to make themselves available to respond to media and public inquiries. Quick turnaround to these inquiries ensure that a piece of digital content can be trusted and clarified (Godler \& Reich, 2017). The last step is consistency which means that users need to provide regular updates on how the development of an issue reported has so far been addressed (Pershad et al., 2018). These updates encourage others to share similar experiences. They also help the audience increase trust levels of shared content and gauge how they could contribute to responding to this emergency. 
Figure 1. Social Media Video Guide

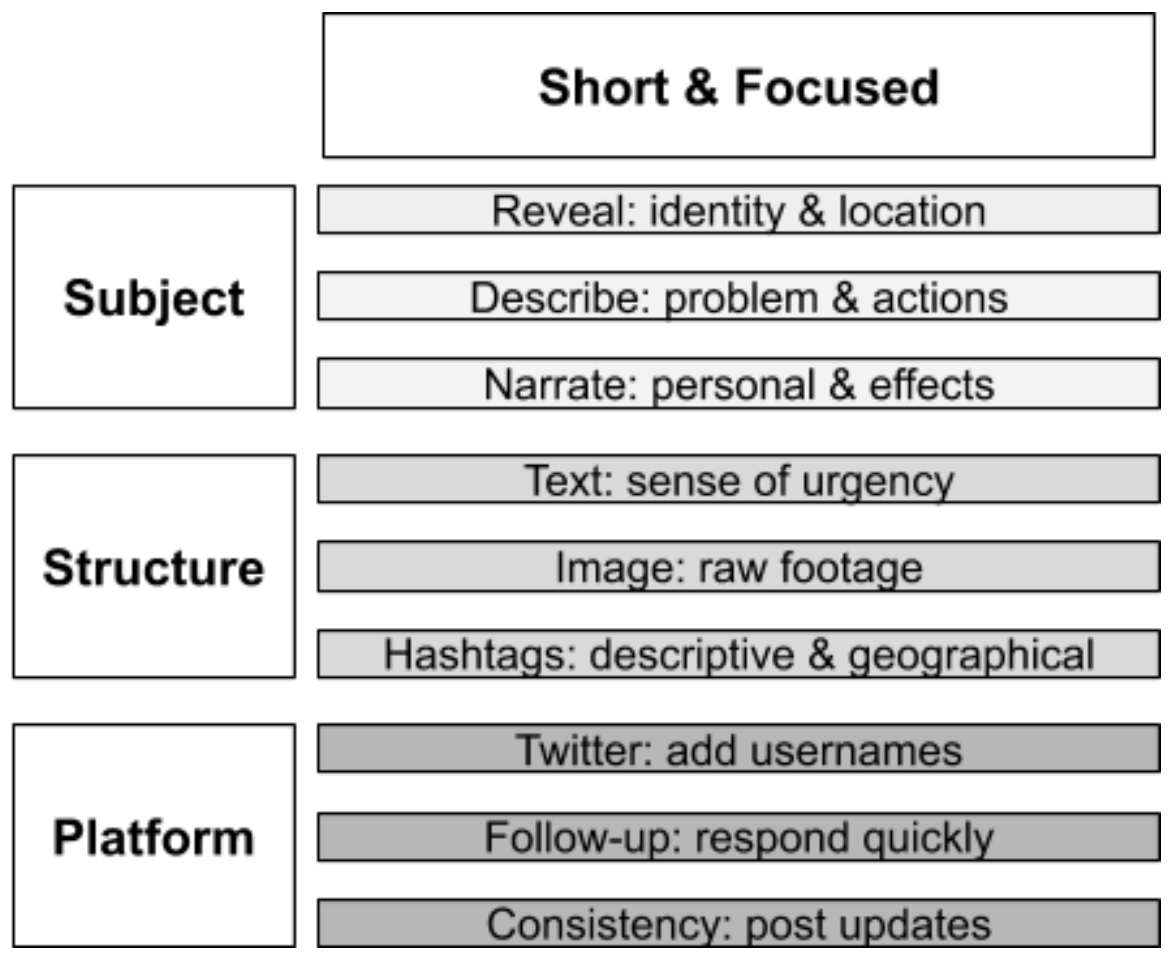

\section{Results}

The effective use of Twitter by an Ecuadorian journalist helped the most vulnerable in Guayaquil. This journalist closely followed the development of this pandemic through international, national and local news. This position allowed the journalist to appraise the initiative of organizing uncollected bodies through a social media platform. The information distributed through Twitter and the journalist's existing professional network amplified the experiences that the relatives of the deceased were facing. It also exposed the failure of the local government to plan and respond to this emergency.

The public service provided by this journalist revealed a disorganized but widespread bottom-up movement. In despair, the most vulnerable recorded their conditions but struggled to translate the severity and magnitude of their experiences into action. It was a voluntary intervention that allowed vulnerable families to have their voices reach authorities and share 
with the country and the international media the tragic effects of the collapse of the public health and emergency systems in Guayaquil.

This event shows that non-professionals can also tap into the power of social media to amplify their concerns and gather support for their messages. The provision of a simple guideline on how raw footage should be recorded, structured and distributed is expected to help the most vulnerable and those working closely with them to grasp the basic lessons of effective communication through social media in times of crisis. Such media training expects to help individuals experiencing harsh conditions draw the attention of local authorities and have them respond to their urgent needs (Bennett \& Pfetsch, 2018).

\section{Discussion}

The most vulnerable members of communities at risk have not yet harnessed the power of social media to draw attention to their livelihood and counterbalance mainstream narratives. They still require the help of media professionals to voluntarily side with them or random individuals to empathize with their plight. The main issues of such deterrents are delay in communication processes, social dependence (Golpayegani et al., 2019), and prolonged and unnecessary suffering. This paper aims to empower vulnerable individuals by providing a simple guideline to amplify their voices in emergencies. It aims to help them directly connect with others as well as authorities and professionals that can help address the urgent situations they are in. It is expected that from such training, these individuals can more effectively start making calls for actions. And they should no longer wait for others to make these calls on their behalf. The expectation of creating and distributing digital stories without intermediaries is that a threat can be earlier identified and mitigated.

There are some assumptions that weaken the implementation of this rhetoric and communication strategy. It is correct to assume that a great number of people from vulnerable groups cannot be characterized as netizens, or those that voluntarily create content for social media platforms. This is because of their limited access to essential resources such as smartphones and the Internet. It can also be wrongly assumed that vulnerable netizens can use the proposed guideline to draw the attention of the media and authorities to every problem they face. The underlying argument in this paper requires a sense of urgency to be in place for the 
validation of a testimonial footage from a bottom-up perspective. Individuals, however, may still draw attention to an upcoming threat if they effectively use social media to explain why an emerging issue requires urgent action and how it might affect the livelihood of a great number of people.

There are also the risks of privacy and safety in registering sensitive events. Individuals recording a personal experience and revealing their identity to the public risk being stigmatized, ostracized and misjudged (MacPherson \& Kerr, 2019). The other risk involved in registering authentic experiences is the environment itself. Spontaneously recording an event may heighten the risks of physical and verbal abuse for the individual doing so (Gregory et al., 2005). Finally, this paper assumes that netizens can directly reach professionals and authorities through Twitter but this assumption does not hold true in many situations.

\section{Acknowledgement}

No conflict of interest to report. No funding to declare.

\section{References}

Baccarella, C. V., Wagner, T. F., Kietzmann, J. H., \& McCarthy, I. P. (2018). Social media? It's serious! Understanding the dark side of social media. European Management Journal, 36(4), 431-438.

Bennett, W. L., \& Pfetsch, B. (2018). Rethinking political communication in a time of disrupted public spheres. Journal of Communication, 68(2), 243-253.

Campbell, R., Martin, C., \& Fabos, B. (2018). Media essentials: A brief introduction. Bedford/St. Martin's.

Caple, H. (2018). News values and newsworthiness. In Oxford Research Encyclopedia of Communication.

Carr, P. R., Pluim, G. W., \& Howard, L. (2018). Engagement with the Mainstream Media and the Relationship to Political Literacy: The Influence of Hegemonic Education on Democracy1. In Democracy 2.0 (pp. 65-81). Brill Sense. 
Enli, G., \& Simonsen, C. A. (2018). 'Social media logic' meets professional norms: Twitter hashtags usage by journalists and politicians. Information, Communication \& Society, 21(8), 1081-1096.

Finkler, W., \& Leon, B. (2019). The power of storytelling and video: a visual rhetoric for science communication. Journal of Science Communication, 18(5), A02.

Godler, Y., \& Reich, Z. (2017). Journalistic evidence: Cross-verification as a constituent of mediated knowledge. Journalism, 18(5), 558-574.

Golpayegani, F., Dusparic, I., \& Clarke, S. (2019). Using social dependence to enable neighbourly behaviour in open multi-agent systems. ACM Transactions on Intelligent Systems and Technology (TIST), 10(3), 1-31.

Green-Pedersen, C., \& Stubager, R. (2010). The political conditionality of mass media influence: When do parties follow mass media attention?. British Journal of Political Science, 40(3), 663-677.

Gregory, S.; Caldwell, G.; Avni, R.; Harding, T. (2005). Video for Change: a guide for advocacy and activism. Pluto Press London, Ann Harbor, MI.

Grosser, K. M., Hase, V., \& Wintterlin, F. (2019). Trustworthy or shady? Exploring the influence of verifying and visualizing user-generated content (UGC) on online journalism's trustworthiness. Journalism Studies, 20(4), 500-522.

Hong, S., \& Kim, S. H. (2016). Political polarization on twitter: Implications for the use of social media in digital governments. Government Information Quarterly, 33(4), 777-782.

Jost, J. T., Barberá, P., Bonneau, R., Langer, M., Metzger, M., Nagler, J., ... \& Tucker, J. A. (2018). How social media facilitates political protest: Information, motivation, and social networks. Political psychology, 39, 85-118.

Krutka, D. G., \& Carpenter, J. P. (2016). Participatory learning through social media: How and why social studies educators use Twitter. Contemporary Issues in Technology and Teacher Education, 16(1), 38-59.

Labrecque, L. I., Swani, K., \& Stephen, A. T. (2020). The impact of pronoun choices on consumer engagement actions: Exploring top global brands' social media communications. Psychology \& Marketing.

Lee, J., \& Xu, W. (2018). The more attacks, the more retweets: Trump's and Clinton's agenda setting on Twitter. Public Relations Review, 44(2), 201-213. 
MacPherson, E., \& Kerr, G. (2019). Sport fans' responses on social media to professional athletes' norm violations. International Journal of Sport and Exercise Psychology, 1-18.

ManabaDice [@ManabaDice]. (2020, March 26). Insólito este gobierno. [Tweet]. Retrieved from https://twitter.com/ManabaDice/status/1242986972643307520

MisionesOnline (2020, April 1st). Coronavirus: se viralizó el dramático pedido de un periodista ecuatoriano quien se quiebra ante cámaras por las decenas de muertos en las calles. Retrieved from

https://coronavirus.misionesonline.net/2020/04/01/coronavirus-se-viralizo-el-dramatico-pedido-d e-un-periodista-ecuatoriano-quien-se-quiebra-ante-camaras-por-las-decenas-de-muertos-en-las -calles/

Mortensen, M. (2014). Journalism and eyewitness images: Digital media, participation, and conflict. Routledge.

Nikolinakou, A., \& King, K. W. (2018). Viral video ads: Emotional triggers and social media virality. Psychology \& Marketing, 35(10), 715-726.

Pershad, Y., Hangge, P. T., Albadawi, H., \& Oklu, R. (2018). Social medicine: Twitter in healthcare. Journal of clinical medicine, 7(6), 121.

Pesantes, B. M. [@Blankimonki]. (2020, March 31). En este hilo, para ayudar, publicaré a todos los cadáveres a los que no han recogido. [Tweet]. Retrieved from https://twitter.com/Blankimonki/status/1244784847626874880

Pesantes, B. M. [@Blankimonki]. (2020a, Feb 29). EI IESS desmiente que exista un caso de coronavirus en Guayaquil. [Tweet]. Retrieved from https://twitter.com/Blankimonki/status/1233418505900503040

Pesantes, B. M. [@Blankimonki]. (2020b, March 21). Ese cadáver lleva ya 15 horas sin que se haga nada. Se trata de una adulta mayor que en sus últimas horas de vida presentaba un cuadro de afección respiratoria y tos. [Tweet]. Retrieved from https://twitter.com/Blankimonki/status/1241087530495348737

Ristovska, S. (2016). The rise of eyewitness video and its implications for human rights: Conceptual and methodological approaches. Journal of Human Rights, 15(3), 347-360.

Rocha, A., Scheirer, W. J., Forstall, C. W., Cavalcante, T., Theophilo, A., Shen, B., ... \& Stamatatos, E. (2016). Authorship attribution for social media forensics. IEEE Transactions on Information Forensics and Security, 12(1), 5-33. 
Shapiro, M. A., \& Hemphill, L. (2017). Politicians and the policy agenda: Does use of Twitter by the US Congress direct New York Times content?. Policy \& internet, 9(1), 109-132.

Straus, J. R., \& Glassman, M. E. (2016). Social media in congress: The impact of electronic media on member communications. Congressional Research Service.

Street, J. (2010). Mass media, politics and democracy. Macmillan International Higher Education.

Wang, R., Liu, W., \& Gao, S. (2016). Hashtags and information virality in networked social movement. Online Information Review.

Yang, X., Chen, B. C., Maity, M., \& Ferrara, E. (2016, November). Social politics: Agenda setting and political communication on social media. In International Conference on Social Informatics (pp. 330-344). Springer, Cham. 